En cambio el arte austero de la Contrarreforma le parecía antipático, y la arquitectura manierista francamente desagradable. Así pues, pese a sus esfuerzos por ser tolerante e imparcial, nunca pudo expresar otra cosa que respeto, sin el menor calor, por El Escorial.

Bernard Bevan será recordado por sus numerosos amigos y colegas con admiración por su entusiasmo y su originalidad, y con afecto por su solicitud, amabilidad y buen carácter. Su Historia de la arquitectura española, tal como fue escrita originalmente hace setenta años y publicada en versión española en 1950 y luego en 1970, se seguirá leyendo sin duda como un clásico de su época, y seguramente mantendrá largo tiempo su importancia para la historia del gusto y de la crítica.

JOHN BURY

\title{
APROXIMACIÓN A LA ICONOGRAFÍA DE LAS ÓRDENES RELIGIOSAS EN LA AZULEJERÍA VALENCIANA DEL SIGLO XVIII
}

El esplendor que caracteriza la azulejería valenciana del siglo xviII es notorio en la representación de santos y programas hagiográficos, rodeados de motivos y formas decorativas de singular belleza. Los pintores de azulejos, dibujan en estarcido sobre el esmalte estannífero, con perfiles en cobalto o manganeso de trazo fino (paños de azulejos de la Iglesia de Nuestra Señora de los Angeles en Chelva) (Fot. 12) o trazo grueso, para conseguir volúmenes y sombras como en el cuadro de azulejos de Santa Teresa en la fachada del antiguo convento del Carmen en Valencia. Los colores amarillos, ocres, naranjas, azules, violetas y verdes, iluminan un esmalte muy lechoso, característico de los talleres valencianos en azulejos que cubren suelos, o revisten muros en iglesias, ermitas, conventos o palacios. Estas obras fueron ponderadas por investigadores como Tormo Monzó, pionero en el estudio monográfico de la azulejería valenciana del setecientos en la arquitectura religiosa ${ }^{1}$.

En las escenas e imágenes que se representan, reconocemos un sentimiento piadoso que sigue apegado a la tradición, desapareciendo casi por completo complejas representaciones, para pasar a una reflexión más directa entre el artista que realiza la obra y las propias fuentes de inspiración.

Las imágenes dibujadas tienen los elementos iconográficos que les caracterizan y cuando la representación conlleva cierta complejidad, una filacteria o rótulo con el nombre del santo facilita la lectura iconográfica. El repertorio de los atributos de los santos, se reconocen como los símbolos que hacen referencia a su actividad (los útiles de trabajo de San José en la iglesia de los Santos Juanes de Meliana), los instrumentos del martirio (la rueda de molino de San Vicente en la iglesia de San Vicente mártir de Guadasuar) o las virtudes por las que tradicionalmente son reconocidos en la iconografía cristiana.

La devoción local favorece la representación de imágenes cuyos hechos y milagros se han destacado en Levante (San Vicente Ferrer, Santo Tomás de Villanueva, San Luis Beltrán). Estas advocaciones se popularizan en los retablos callejeros como expresión devocional colectiva. La obra de este género, llevó a crear conjuntos como el de la fachada de la iglesia del convento de

1 Tormo Monzó, E., «El arte barroco valenciano». Arte español. 1920-21. Tormo Monzó, E., Guías de Levante. Provincia valenciana y murcia. Madrid, 1926. Véase: Pérez Guillén, I., La pintura cerámica valenciana del siglo XVIII. I.A.M. Valencia, 1991. 
los capuchinos en Albaida, utilizando el soporte cerámico para la pintura religiosa en exteriores ${ }^{2}$.

Los temas y santos Carmelitas dibujados sobre el esmalte se conservan en las fachadas de las casas, en el interior de iglesias formando parte de otras composiciones cerámicas, como en la «iglesia-museo» de la Santa Sangre de Liria y en las imágenes de los santos rodeados de preciosos medallones ovalados del convento de San José en Valencia.

Uno de los conjuntos más destacados de las series iconográficas interpretadas en azulejos, se encuentra en la iglesia convento del siglo xIII del Carmen de Requena. Fue el primer convento que se fundó en Castilla por los infantes de la Zerda y el de más extensión según Castañeda y Alcover ${ }^{3}$. Los paños de azulejos de las últimas décadas del siglo xviII, recorren la iglesia con alegorías de la orden del carmelo, el profeta fundador y los primeros santos y personajes reales que defendieron y divulgaron la orden.

Los azulejos se distribuyen en grandes paneles de $1,48 \mathrm{~cm}$ con los santos de la orden, situados frontalmente a manera de esculturas-nicho, junto con rajolas de motivo vegetal. En algún friso, los azulejos aparecen mal casados y desordenados, como restos de una más extensa decoración cerámica. En azul de cobalto se dibujan los perfiles de los santos del carmelo y de los ángeles que portan símbolos de la orden, con coloraciones de verdes y naranjas.

Estas composiciones se adornan con preciosas formas ornamentales de guirnaldas de flores y querubes con el escudo y símbolos de la orden. En la primera capilla (transepto) se representa a los santos Elías y Eliseo junto al monte Carmelo. En el cuadro que es simétrico al anterior por las dimensiones de $84 \times 84 \mathrm{~cm}$ y que se sitúa en el lado del evangelio se interpreta la asombrosa escena que describe el Libro de los Reyes sobre los Hechos del profeta Elías, cuando el profeta es arrebatado hacia el cielo en un carro de fuego (prefiguración de Cristo) ante la presencia de su discípulo Eliseo. El profeta Elías, también forma parte del programa iconográfico de los santos carmelitas sobre los azulejos de las capillas de la iglesia. Aparece representado con los atributos que le caracterizan, la espada flamígera, como alusión a los sacerdotes de Baal (1 Reyes, XVIII,40) y la túnica y capa de piel, símbolos del santo ermitaño que también identificamos en la imagen del profeta Eliseo, junto con una jarra de aceite, atributo del milagro del santo cuando multiplica el aceite a una pobre viuda según rezan los textos sagrados (II Reyes IV, 1-7). El ciclo en la capillas de la nave se abre con las figuras que portan los textos sagrados alegóricos a la fundación de la orden de 1 Carmelo «RELIGIO CARMELI TARVM ALPPA OMEGA», «PRIMO VIVENS \& LV TIMO MORIENS» (Fig. 9).

Las alegorías también se representan en los emblemas que sujetan los angelitos dibujados en el frente de los pilares que dan a la nave central, junto con el escapulario y escudo de la orden, las flores de lis símbolo de la monarquía francesa en reconocimiento a San Luis por favorecer la divulgación de la orden en occidente, y la heráldica de la corona de Castilla.

En uno de los paños de azulejos que se encuentran en el templo, se diferencia claramente una iglesia sobre la palma de una mano, como templo fundacional. Quizás estemos hablando el oratorio construido en el monte Carmelo y dedicado a María por Agabus ${ }^{4}$. Los carmelitas consideraban que la Virgen perteneció a la orden, lo que explica su gran devoción.

2 En el año 1839, las autoridades valencianas ordenaron que fueran destruidos todos los retablos de las calles de la ciudad, haciendo caso omiso de las peticiones de algunos vecinos, que reclamaban su permanencia. Esta normativa explica, en parte, los escasos ratablos de azulejos que se conservan en la ciudad y localidades valencianas. Véase: Garín Ortiz de Taranco, F. M., Catálogo monumental de Valencia. Valencia, 1983.

3 Castañeda y Alcover, V., Relaciones geográficas, topográficas e históricas del Reino de Valencia. 3 vols. Madrid, 1919. Rutes d'aproximació al patrimoni cultural valenciá. n. 11 . Requena-Utiel. Generalitat valenciana, 1985.

4 Mâle, E., L'art religieux aprés le Concile de Trente. pág. 444. 


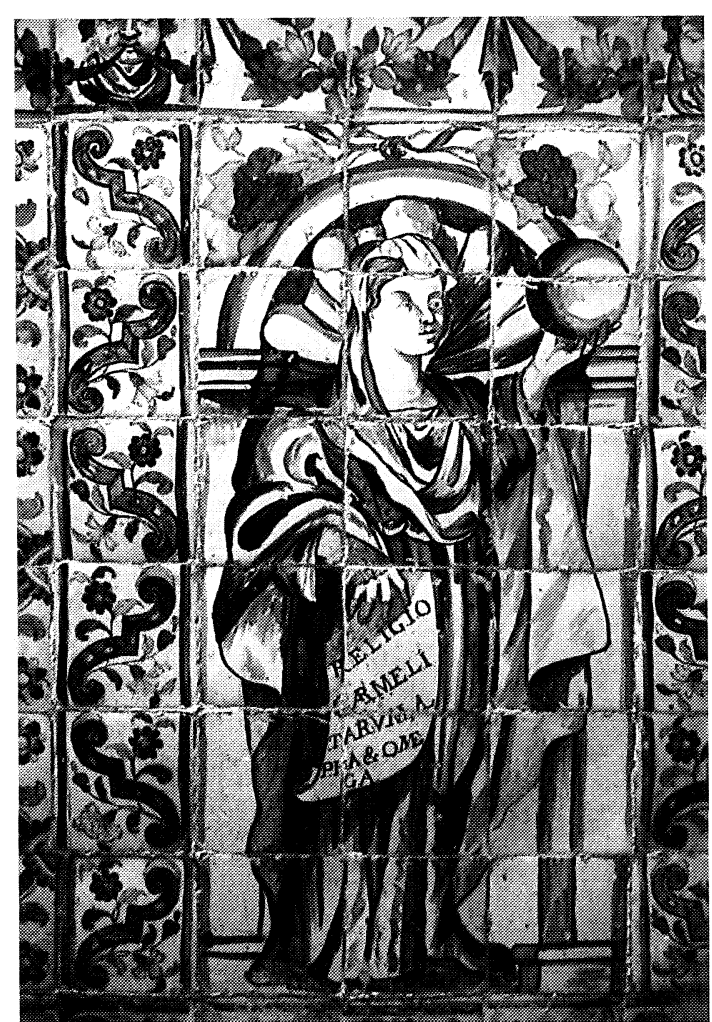

9

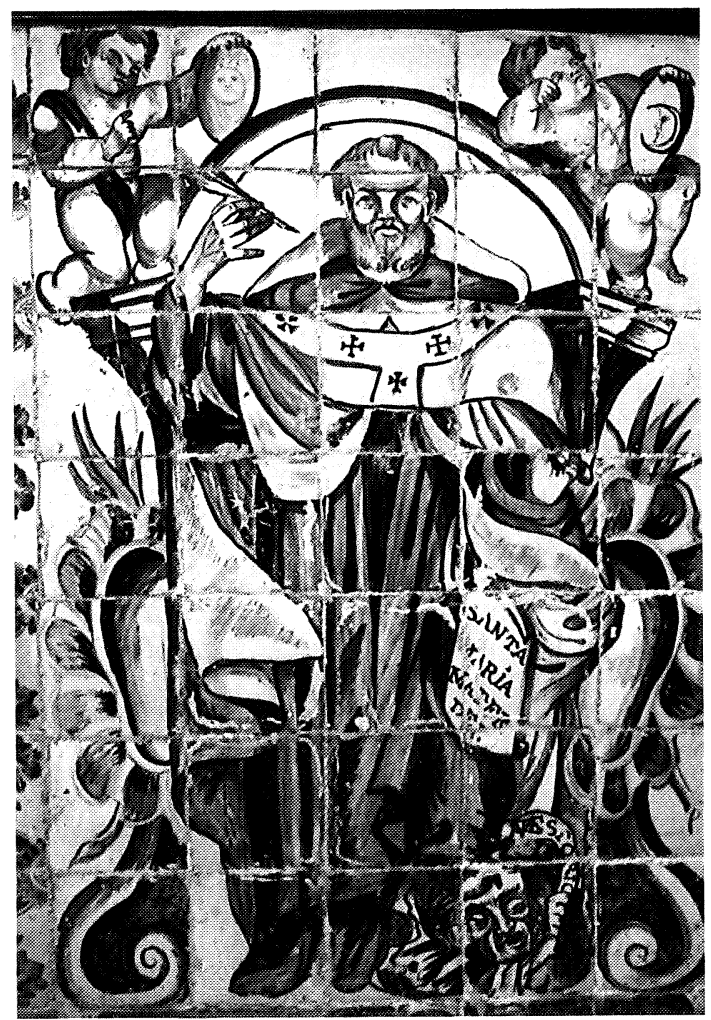

10

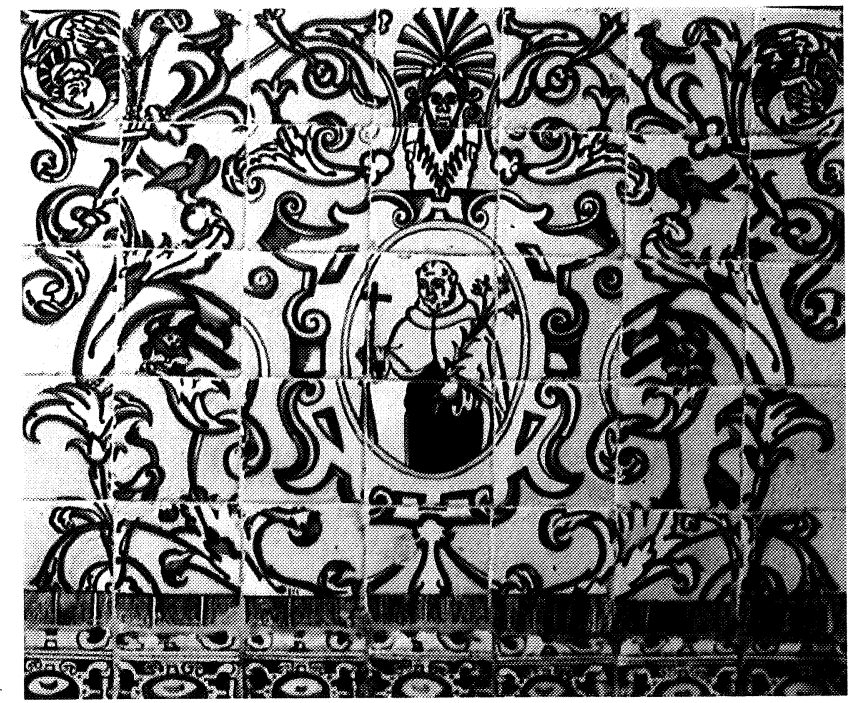

Figs. 9 y 10. Alegoría de la Orden del Carmelo y San Cirilo. Iglesia del Convento del Carmen en Requena.

Fig. 11. San Alberto. Iglesia del Convento de San José en Valencia. 
Entre los santos que difunden el fervor del carmelo en Oriente, se representa a San Cirilo, Patriarca de Alejandría que hizo vida de ermitaño en el monte Carmelo en el año 451. En el cuadro de azulejos aparece con los atributos que lo identifican como un fiel defensor de la Virgen, «Theotocos» con la frase que declaró ortodoxa «SANTA MARIA MATER DEUS», contra la herejía nestoriana en el Concilio de Efeso. En esta imagen aparece con la cabeza de un diablo, sobre la que reposa el pie del santo. En la mano derecha sujeta una pluma como hombre de estudio que fue (Fig. 10).

San Alberto patriarca de Jerusalén fue incorporado en el siglo xvir como santo de la orden del carmelo. Fue autor de la regla de la orden en los primeros años del siglo xiII, por lo que es considerado el segundo fundador. Los atributos que diferenciamos sobre el panel de azulejos lo identifican con la dedicación que tuvo en vida, el libro de fundación, la pluma y la cruz arzobispal. Sobre el arco de medio punto que corona la imagen dos parejas de angelitos sujetan la cruz de dos brazos y un libro abierto con los capítulos de la fundación de la orden.

La latinización de la orden comienza con la labor de San Angel y San Alberto de Sicilia. San Angel de Jerusalén fue anacoreta y apóstol martirizado en Sicilia. En los azulejos aparece dibujado con la pluma y las tres coronas, símbolos de la ciencia, de la virginidad y del martirio del santo.

La orden siguiendo a Mâle, permanece en Palestina hasta la llegada de las cruzadas en que se introduce en Francia por San Luis, representado en la segunda capilla del lado de la epístola, junto al profeta Eliseo.

Santa Teresa promotora de la reforma del carmelo, se representa en fachadas a manera de pequeños retablos (antiguo Museo de Bellas Artes en Valencia) o en revestimientos de iglesias como en el convento de San José en Valencia. La iglesia del convento de San José 5 conserva azulejos de $13,5 \times 13,5 \mathrm{~cm}$ que revisten un panel de $86 \mathrm{~cm}$ en la capilla del lado de la epístola con dos santos carmelitas. Santa Teresa se dibuja en el interior de un medallón ovalado, rodeado de formas decorativas renacentistas, a base de máscaras, pájaros, róleos... Los motivos siguen la decoración de las "ferronéries» que dibujaron los pintores de los talleres cerámicos talaveranos en los siglos XVI y XVII junto con las formas que rodean el medallón de los santos carmelitas, la cenefa de azulejos de "perla». El trazo en manganeso y la escueta paleta cerámica naranja y azul la reconocemos también en las series bicolor de la cerámica talaverana. En el revestimiento de la misma capilla se encuentra la imagen de San Alberto, fundador de las reglas de la orden en el siglo XIII (fig. 11).

De la orden de los Franciscanos se conservan ejemplos en la entrada al claustro del convento de Gilet con el santo en éxtasis o en el interior de la ermita de Cuevarruz, en series que narran la vida de San Antonio Abad o en escenas aisladas predicando a los peces en la iglesia de Bocairente y con los atributos personales la azucena, el Niño Jesús o el libro abierto en el Museo de Cerámica González Martí.

Las formas decorativas son también muy frecuentes, tal y como se pone de relieve en la imagen de San Pascual (Museo Nacional de Cerámica González Martí), al ahondar el pintor cerámico en preciosos esquemas ornamentales, como las pequeñas flores en forma de guirnaldas o medallones en cuyo interior se representa el santo protector con el cáliz, que claramente lo identifica.

En el Hospital de Pobres Sacerdotes, la orden mendicante de los Dominicos y la iconografía del santo fundador, está representada en los revestimientos de la celda de San Luis Beltrán. La labor misionera del santo fundador, la tea encendida que sostienen entre los dientes un perro y la estrella sobre la cabeza del animal ilumina con la fe todos los lugares donde predica, razón por la que el perro se apoya en un panel cerámico de Puçol en la bola del mundo.

5 Madoz, P., Diccionario geográfico, estadístico e histórico de España, 1848. 

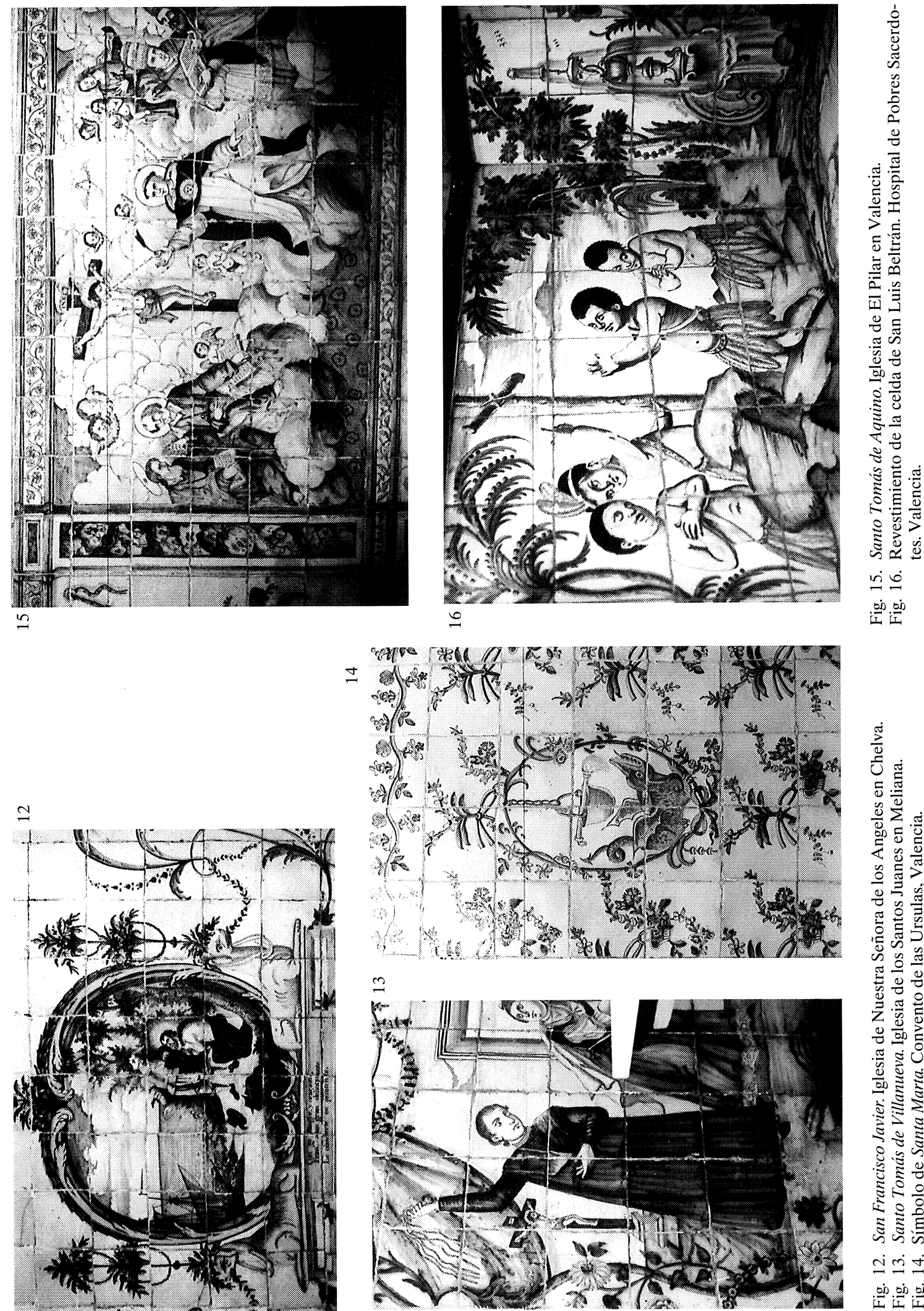
Los santos que difunden el espíritu de la orden, Santo Tomás de Aquino y Santa Catalina de Siena, están dibujados en los paños cerámicos de la capilla del Sagrado Corazón dedicada a los Santos dominicos en la iglesia de El Pilar en Valencia, edificada y remozada entre los años 1667 y $1730^{6}$.

El conjunto de la iglesia es churrigueresco en su interior, con zócalos de azulejería historiada, de señalado interés en la primera y segunda capilla del lado del evangelio y primera y tercera capilla del lado de la epístola.

Los revestimientos cerámicos de la capilla del Sagrado Corazón están fechados en el año 1783. Los azulejos son el soporte de un minucioso trazado en manganeso y de una policromía plena, de fondo blanco y colores verde, marrones, negro, morado. El marco es ornamental con orla de formas vegetales y pilastras jaspeadas.

En el revestimiento derecho de la capilla del Sagrado Corazón se desarrolla la composición de Santa Catalina de Siena ante el papa Urbano VI rodeada de un precioso marco arquitectónico (es el pasaje relativo a las exhortaciones de la santa en el Cisma de Occidente).

En el revestimiento izquierdo se representa a Santo Tomás de Aquino como doctor de la iglesia. Unos angelitos portan en los dos revestimientos cerámicos los símbolos de los santos dominicos que aluden a la condición de Doctor de la iglesia de Santo Tomás y al padecimiento de Santa Catalina de Siena, la corona de espinas, que aparece junto con otros atributos de Santa $\mathrm{Ca}$ talina de Alejandría, la corona como distintivo real y la palma del martirio. Catalina de Alejandría gozó de la inspiración divina para confundir a los filósofos paganos, como Santa Catalina de Siena que fue iluminada por el Espíritu Santo par hablar con elocuencia y energía a los papas Gregorio XI y Urbano VI. Santa Catalina de Siena defiende la fe en el púlpito, rodeada de los símbolos, el crucifijo, la corona de espinas y las llagas que se ven impresas en su mano, que la identifican con Cristo, con el amor y el sufrimiento que soportó y gozó en vida.

La imagen de Santo Tomás de Aquino considerado quinto doctor de la iglesia, tiene gran veneración en los siglos XVII y XVIII, como defensor de la Eucaristía (fig. 15). El paño cerámico de la iglesia de El Pilar en Valencia, es una clara alegoría a su veneración como Padre de la iglesia, culto que se empezó a rendir después de anunciarlo Pío V en el año 1567. Santo Tomás en la gloria, está en presencia de Cristo crucificado y la Virgen con el Niño; sobre su cabeza, el Espíritu Santo le ayuda a mantener la fe y la inspiración divina. Dios le asiste por mediación de los apóstoles Pedro y Pablo según narra Santiago de la Vorágine. San Pedro y San Pablo son los santos que en el cuadro de azulejos representan a la iglesia apostólica, mientras que San Agustín y San Gregorio son los padres de la iglesia doctrinal. Los atributos de Santo Tomás aparecieron dibujados según Mâle en el año 1610 por Otto Venius, en la composición cerámica los identificamos como el sol que brilla sobre el pecho, su sabiduría; la pluma y el libro abierto, su doctrina, conciliación de la filosofía aristotélica y agustiniana, que le llevó a renunciar al arzobispado que el papa Clemente IV le ofreció en Nápoles.

A la vía contemplativa y de acción de Santa Catalina de Siena y Santo Tomás de Aquino se une la obra misionera de dos santos dominicos que luchaban contra la herejía: San Luis Beltrán y San Vicente Ferrer. La devoción a estos santos, explica los numerosos cuadros de azulejos que iluminan capillas y fachadas de las casas valencianas como si fueran pequeños retablos barrocos.

San Luis Beltrán llamado Apóstol de Indias, goza de una singular representación iconográfica en el Hospital de Pobres Sacerdotes, sobre los muros de la galería principal del primer piso

6 Escolano, G., Décadas de la historia de la insigne y coronada ciudad y Reino de Valencia. Valencia, 1879, pág. 63. Teixidor. Antigüedades de Valencia. Valencia, 1895-96. Vilanova y Pizcueta, F., Guía artística de Valencia. Valencia, 1922, pág. 137-38. Aldana Fernández, S. "Juan Pérez Castiel y el barroco valenciano». B.S.C.C., 1968, pág. 56. Garín Ortiz de Taranco, F. M. Ob. cit., pág. 270. 
que recuerdan los milagros y hechos de la vida del santo y en la celda del hospital, hoy capilla, donde el santo vino a parar durante su enfermedad ${ }^{7}$ (fig. 16).

Las escenas de los cuadros de azulejos de los primeros años del siglo xix situados en la galería son los siguientes: San Luis Beltrán recibe el hábito de la orden de Santo Domingo en Valencia, de manos del P. Juan Mico en el año 1544; la amenaza de un noble al santo disgustado por sus predicaciones, con una pistola que se transforma milagrosamente en crucifijo; la llaga que tuvo durante muchos años en una pierna la cura el Patriarca Juan de Ribera; la poca salud que le acompañó durante toda su vida, la interpreta el pintor cerámico en cuadro en donde la Virgen junto a su lecho, le ofrece una taza de caldo. Pese a su enfermedad se embarcó en Sevilla en el año 1562, para permanecer en América durante siete años, de este período hay una muestra de dos cuadros en los que se representa a San Luis Beltrán cuando es convidado a comer por un encomendero, cuya crueldad se man)fiesta al coger un pan y exprimirlo, brotando de él un chorro de sangre, junto con otro hecho milagroso que aconteció en las selvas americanas. Mientras predicaba al extender los brazos el santo sobre un árbol gigante, dejo impresa la señal de la cruz, convirtiéndose los irfieles al ser testigos de tan sorprendente suceso.

En el año 1575 es elegido Prior de Santo Domingo, la distinción más alta que logró el santo. El buen gobierno que hizo de esta casa, queda reflejado en el cuadro en que San Luis Bertrán remedia a "pobres, mendigos, estudiantes y vergonzantes». Su enfermedad que se agrava en el año 1581 le obliga a quedarse en cama y ocupar durante dos meses la celda del Hospital de Pobres Sacerdotes, donde también celebraba misa los días que su dolencia podía permitírselo, como vemos en los azulejos de la galería. Recibió el Santo Viático en la celda que ocupaba durante su enfermedad, escena que se representa en el panel cerámico, que cierra la serie de la vida de San Luis Beltrán, junto a otros personajes que presencian tan señalado hecho, el Patriarca Juan de Ribera, el obispo titular de Marruccos y auxiliar de Valencia y el gobernador Jaime Ferrer.

En el piso principal se encuentra la capilla que ocupó San Luis Beltrán durante su enfermedad. Sobre esta capilla Madoz señala en su Diccionario geográfico, histórico y estadístico de España... «EI cuarto más inmediato a la celda del racional contiene una escena de figuras corpóreas de tamaño natural, que interesa por sus circunstancias y personajes que en ella aparecen: figura a San Luis Beltrán incorporado en la cama, teniendo a la cabecera al venerable... San Juan de Ribera... y a los pies al piadoso y entendido pintor y sabio literato Fr. Nicolás Pedro Factor, vestido con sus trajes peculiares, y sobre una mesilla platos, tazas, vasos con medicinas u otras cosas. En el piso de hermosos ladrillos barnizados están pintadas las dos Américas con varios geroglíficos alusivos a la vida de San Luis, como apóstol de las Indias, y el que tenía cuando habitaba el santo, se conserva pegado a las paredes y cubierto con cristales». La disposición de los personajes que describe Madoz, es idéntica a la que aparece en la ilustración publicada en la obra de Almela y Vives "Valencia y su Reino " del año 1945. Es interesante señalar la lámina grabada por Julián Mas del cuarto estancia de San Luis Beltrán ${ }^{8}$, por la similitud con el estado actual que presenta la capilla.

En el año 1780 se hicieron los paños cerámicos de la capilla del santo dominico, como el resto de los paneles que revisten el hospital y capilla del Milagro. En la segunda galería figura en un cuadro de azulejos la fecha de la restauración de dicho hospital que reza así: «DE REHEDIFICACION DE ESTE ANTIQUISSIMO HOSPITAL DE POBRES SACERDOTES EN EL AÑO 1782 LA MAYOR PARTE A EXPENSAS DEL ILLmo EXCmo DON FRANCISCO FABIAN Y FUERO DIGNISSIMO ARZOBISSPO DE ESTA CIUDAD».

\footnotetext{
7 Texidor, J., Ob. cit. Véase: Garín Ortiz de Taranco, F. M.: Ob. cit., pág. 180.

8 Madoz, Pascual, Diccionario geográfico-estadístico historia de España y sus posesiones de Ultramar, Tomo XV, Madrid, 1848 , pág. 393.
} 
El más elocuente de los predicadores, como señala Male, fue San Vicente Ferrer, patrón de Valencia, lo que explica los numerosos cuadros de azulejos que sobre la figura del santo se conservan en el Museo de Cerámica González Martí, en la iglesia de la Santa Sangre en Liria, en El Pilar de Valencia, la iglesia de los Santos Juanes de Meliana o en fachadas de casas e iglesias.

Las formas iconográficas siguen idéntica tipología en los ejemplos estudiados: el santo viste el hábito de las orden de los Dominicos, con una llama sobre la frente y dos grandes alas (la iglesia de El Pilar en Valencia) porque se le compara con el ángel del Apocalipsis. La elocuencia de sus palabras se refleja en el libro que sujeta junto con un ramo d azucenas, alegoría a su castidad. La mitra y el capelo de cardenal se dibujan apartados del santo, por haber renunciado a tales privilegios. Sobre su cabeza campea una filacteria con una frase del Apocalipsis que siempre le acompaña: «TIMETE DOMINUM ET DATE ILLI HONOREM QUIA VENIT HORA JUDICI EIUS» (Apoc. 14,6). Las escenas se refieren a los hechos en vida y milagros del santos en la iglesia de Meliana, El Pilar en Valencia y la Casa Natalicia de San Vicente Ferrer donde se representan escenas populares de los milagros del santo (el milagro del "rogle», el milagro del «mocadoret», del pozo, y el milagro de los barcos cargados de trigo llegando al puerto de Barcelona...). En los revestimientos cerámicos de la iglesia de El Pilar, las composiciones se desarrollan en el interior de medallones de forma ovalada, con filacterias en donde leemos la descripción de los hechos milagrosos del santo: "ANUNCIA LAS NAVES DE BARCELONA». El santo provee de trigo a la ciudad portuaria en tiempo de carestía y hambruna. La resurrección de una muerta en Salamanca es otro de los hechos más salientes de su vida, lectura iconográfica que podemos seguir en el texto de la filacteria: «Mdo TRAER UNA D.ta Y LA RESUCITA EN TETIMo DE SER EL ANGL DL AP.si.».

En los revestimientos de la misma capilla, dos escenas representan episodios de la vida de San Vicente Ferrer, que se narran en sendas cartelas que sujetan angelitos, formando parte de un escenario barroco en una alegoría a la penitencia. «EL MISMO DIA IQUE LLEGABA A LAS POBLACIONES SE FORMABAN PROCESION DE DISCIPLINANTES Y ERA TAN GRANDE EL NUMERO QUE EN TOLOSA LLEGARON A 400». "A LA NOCHE SIGUIENTE ESTANDO EN ORACION OYO UNA VOZ QUE LE DIJO: PERDERIA PRESTO SU VIRGINIDAE), AFLIGIDSE EL ST ${ }^{\circ}$ Y APARESIOLE LA VIRGEN SS. Y DIJO: DIOS SERA TU ESCUDO Y YO TU DEFENSA». El primer panel lo podemos relacionar con la descripción que Huizinga hace sobre la llegada del santo dominico a las poblaciones en las que va a predicar.

En la segunda escena de la misma capilla de la iglesia de El Pilar, la Virgen ayuda a San Vicente a vencer la tentación de Satanás. Luis de Blanes describe los episodios de la Virgen y San Vicente Ferrer en lo que fue celda del santo dominico en el convento de la misma orden en Valencia: «Fue... esta celda santa teatro donde nuestro glorioso vencedor triunfó repetidas veces de Satanás y recibió singulares favores de nuestro Soberano Dios y de la Gran Reina de los Angeles».

Santa Rosa de Lima religiosa terciaria de la orden de Santo Domingo, fue beatificada por Clemente IX y canonizada en 1671 por Clemente X. Sus atributos iconográficos están representados en un precioso cuadro de azulejos del Museo de Cerámica González Martí: la corona de espinas con la que mortificaba su belleza, que como en muchas obras se representa con la corona de flores. Es una de las pocas santas que sujeta al Niño Jesús en sus brazos, comunicación espiritual que vemos reflejada en el panel cerámico y que podemos enlazar con la vía comunicativa, el germen de la orden dominica.

Por su temprana muerte y la divulgación de sus biografías se insiste especialmente, según señala Bernales Ballesteros, en el deleite y dulce expresión de arrobamiento causado por la tierna aparición del Jesús Niño que le coloca la corona de rosas. 
Valencia pasa a ser en el siglo xVIII el centro donde la devoción y gusto por el tema, lleva a encargar al pintor José Vergara el fresco de la capilla dedicada a la santa de un antiguo colegio, que hoy es sede del Ayuntamiento valenciano (1726-1799). La extensión y auge de esta devoción explica el cuadro de azulejos que se representa sobre la santa limeña.

En la iglesia de Nuestra Señora de los Ángeles en Chelva, construida en los últimos años del siglo xvir, hay dos revestimientos cerámicos del año 1790 de la orden de San Ignacio que narran los milagros de San Francisco Javier, uno de los primeros discípulos del fundador de la orden.

Las leyendas del pedestal, describen las luminosas escenas con los hechos milagrosos del santo: «DEXO EL DEMONIO A LOS CUERPOS PORQUE XAVIER LO MANDO.I AUN DE NIÑOS SE VALIO». «I CON SU SANGRE Y ORACION FRANCISCO AUN GRAN DELINCUENTE LE CONVIERTE EN PENITENTE». La leyenda de este revestimiento narra la conversión del capitán del barco por San Francisco Javier, antes de partir hacia Oriente (fig. 12).

Santo Tomás de Villanueva (1488-1555) monje agustino, tuvo especial devoción en la ciudad de Valencia por su arzobispado. Su vida se caracterizó como reflejan los cuadros de azulejos de la iglesia del siglo XviII de los Santos Juanes de Meliana, por su rechazo a la tentación y por su generosa caridad, bondades que son los atributos que reconocemos en el panel de la iglesia de los Santos Juanes, la bolsa de dinero, el báculo y la mitra arzobispal, símbolos que también aparecen representados en la imagen del Santo que conserva el Museo de Cerámica González Martí (Fig. 13).

Los símbolos de los santos gozan de una rica lectura iconográfica en la azulejería barroca valenciana del siglo xviII. Los motivos se dibujan en el centro del revestimiento cerámico, rodeados de rocallas, frutos, flores, guirnaldas, aves. En la iglesia del convento de las Úrsulas de Valencia, destaca el propio emblema de Santa Úrsula con la diadema de flores que rodea la palma del martirio, la saeta instrumento de su martirio y el estandarte, atributo de la defensa de su virginidad. En otro de los revestimientos cerámicos de la iglesia, el símbolo del amor divino representado por el carozón traspasado por una flecha lo relacionamos con San Agustín, porque la regla de las Úrsulas, se basa en la agustiana.

La imagen bíblica de Santa Úrsula la reconocemos en la misma iglesia, en los atributos de Santa Marta: el dragón (el pecado) que describe la Leyenda Dorada, transformado cuando la santa lo unge con agua bendita (fig. 14).

Araceli Cabezas

Dra. en Historia del Arte 